\title{
Signet ring cell carcinoma of the colon radiologically simulating ileocecal tuberculosis
}

\author{
WC PETER KWAN, MD, FRCPC, HI FREEMAN, MD, FRCPC, FACP
}

WCP KWAN, HJ FREEMAN. Signet ring cell carcinoma of the colon radiologically simulating ileocecal tuberculosis. Can J Gastroenterol 1992;6(6):341344. A 65-year-old East Indian woman with episodic vomiting and anemia had radiological evaluations showing calcified lymph nodes in the abdomen and chest, with narrowing of the ileocecal valve and ascending colon suggesting the possibility of ileoceal tuberculosis. Evaluations subsequently proved this to be a signet ring cell carcinoma of the colon with infiltration of the terminal ileum.

Key Words: Crohn's disease, Ileal stenosis, Inflammatory bowel disease, Intestinal tuberculosis, Signet ring cell colon cancer

\section{Cancer des cellules en bague du côlon simulant la tuberculose iléo-caecale à la radiologie}

RÉSUMÉ: Une Antillaise de 65 ans présentant des épisodes de vomissements et de l'anémie a subi des analyses radiologiques qui ont révélé des ganglions lymphatiques calcifiés au niveau de l'abdomen et du thorax, ainsi qu'un rétrécissement de la valvule iléo-caecale et du côlon ascendant, ce qui laisse supposer un diagnostic possible de tuberculose iléo-caecale. Les examens subséquents confirment qu'il s'agit en fait d'un cancer des cellules en bague du côlon avec infiltration de l'iléon terminal.

Department of Medicine (Gastroenterology), University Hospital and University of British Columbia, Vancouver, British Columbia

Correspondence and reprints: Dr WC Peter Kwan, Gastroenterology, ACU-F-137, University Hospital (UBC), 2211 Wesbrook Mall, Vancouver, British Columbia V6T IWV5. Telephone (604) 822-7216

Received for publication January 10, 1992. Accepted July 15, 1992
IGNET RING CARCINOMA OF THE
colon is an unusual colonic mucinous adenocarcinoma. Because of its infiltrative nature, it may produce radiological changes that mimic other diseases such as ischemic colitis or Crohn's disease. In the present report, a case of signet ring cell carcinoma of the cecum involving the ileocecal valve and terminal ileum that simulated ileocecal tuberculosis is described.

\section{CASE PRESENTATION}

A 65-year-old East Indian woman who emigrated to Canada nine years previously from India presented with a five-year history of recurrent nausea, vomiting and diffuse abdominal discomfort. Diagnostic laparotomy done in a community hospital at the onset of symptoms identified no cause. No barium enema examination or endoscopic studies were performed prior to surgery. There was no history of rectal bleeding, altered bowel habit, fever or weight loss. In 1981 she was exposed to a sister with active pulmonary tuber- 


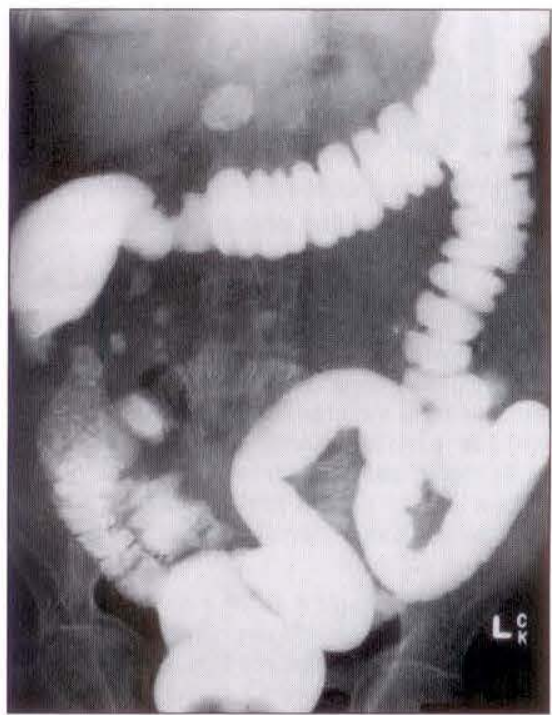

Figure 1) Barium enema showing fixed and stenotic terminal ileum, cecum and ascending colon. Calcified abdominal lymph nodes are present

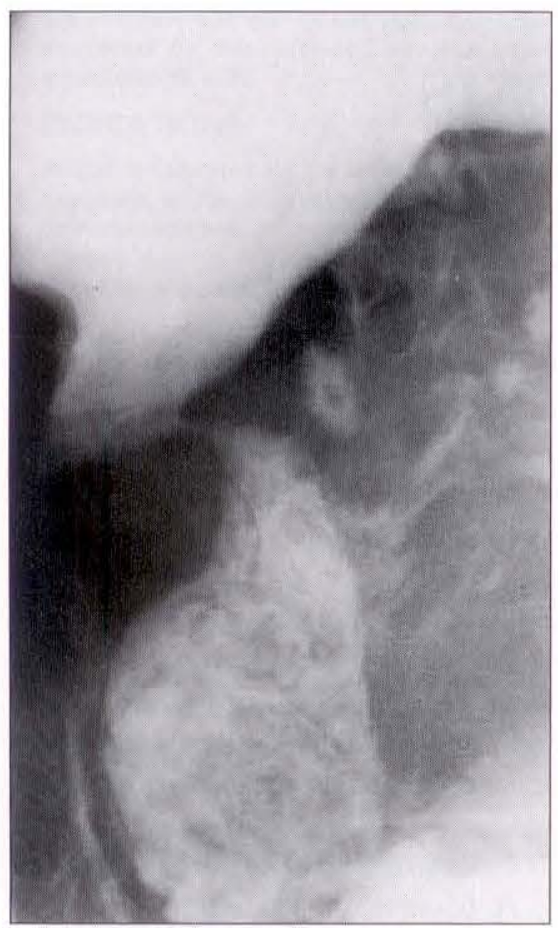

Figure 2) Detailed radiographic view of ileocecal region showing featureless terminal ileum with rigid stenosis

culosis. The details of her surveillance were not available but she did not receive antituberculous treatment and she was not deemed to have active pulmonary tuberculosis. In March 1991, a barium swallow suggested multiple gastric erosions but gastroscopy failed to demonstrate any lesion.
The patient was admitted to University Hospital in August 1991 for further investigation because of persistent abdominal pain and nausea. Physical examination revealed an obese woman with a normal chest and abdominal examination; fecal occult blood testing was positive. She was anemic with hemoglobin $109 \mathrm{mg} / \mathrm{L}$ and a mean cell volume of $68 \mathrm{fL}$. Iron profile confirmed iron deficiency with ferritin 8 $\mu \mathrm{g} / \mathrm{L}$. An air contrast barium enema showed a grossly abnormal cecum with contraction and loss of normal mucosal outline while the ileocecal valve was stenotic and fixed (Figure 1). Cecal ab. normality extended up the ascending colon to the region of the hepatic flexure. Several calcific densities were present consistent with calcified lymph nodes. Distal terminal ileum was feautreless and appeared dilated (Figure $2)$. Chest radiographs revealed a calcified density in the right upper lobe consistent with previous granulomatous disease. Computed tomography scan of the abdomen and pelvis revealed a thickened cecum, ascending colon and distal terminal ileum.

These radiological changes suggested possible tuberculous involvement of the distal terminal ileum and ascending colon. Differential diagnoses included Crohn's disease, amebiasis and a colonic neoplasm. The patient had a negative tuberculosis skin test (5 TU) and she was not anergic.

The carcinoembryonic antigen was $1.2 \mu \mathrm{g} / \mathrm{L}$ (normal less than $4 \mu \mathrm{g} / \mathrm{L}$ ). Stool cultures and examinations for parasitic pathogens were negative.

Colonoscopy revealed an abruptly narrowed lumen in the ascending colon; the cecum could not be intubated. The colonic mucosa was extremely friable and abnormally thickened; biopsies of these thickened mucosal folds demonstrated signet ring cell carcinoma.

Laparotomy revealed a firm $6 \mathrm{~cm}$ mass in the region of the cecum and terminal ileum. There was a $1.5 \mathrm{~cm}$ calcified lymph node in the portal region. The omentum was closely allied to the tumour but otherwise there were no obvious signs of local extension. A right hemicolectomy was performed with a resection of a portion of the involved terminal ileum. Histologically, resection margins were free from tumour, and signet ring cells extended through the wall of the cecum and into distal terminal ileum (Figures 3,4). In some sections of terminal ileum, scattered signet rings cells were seen infiltrating the mucosal lamina propria (Figure 5). There were tumour deposits in two mesenteric lymph nodes. Other lymph nodes showed only calcification (no tumour deposit or evidence of prior tuberculosis).

The patient did well following surgery. Since there was lymph node involvement, adjuvant chemotherapy with 5-fluorouracil and levamisole was offered (1), but the patient refused treatment.

\section{DISCUSSION}

Signet ring cell carcinoma of the colon is an unusual adenocarcinoma that was first described in 1951 as a 'linitis plastica' type of colon cancer (2). The tumour does not appear to follow the hypothetical polyp-cancer sequence suggested for more typical colonic adenacarcinomas. Although it is known to be uncommon, the exact incidence of colonic signet ring cell carcinoma has not been determined. One series suggested it could be found in approximately $1.5 \%$ of all cases of colonic cancer (3), but figures as low as $0.1 \%$ have been reported (4). The clinical and radiographic features have been reviewed (5) - most reports indicate that patients with signet ring cell colon cancer are younger than those with the usual colonic adenocarcinoma and that the initial clinical features commonly may mimic inflammatory or ischemic diseases of the colon because of their radiographic appearances on barium enema (6).

The presented patient had a prolonged history of abdominal symptoms consistent with intermittent intestinal obstruction. Laparotomy done five years earlier was normal. Although it is difficult to accept that an ileocecal tumour was present five years earlier, no other explanation of the symptoms was evident; early tumour involvement in the ileocecal valve region may have resulted in obstructive symptoms. Furthermore, experience from Italy indi- 


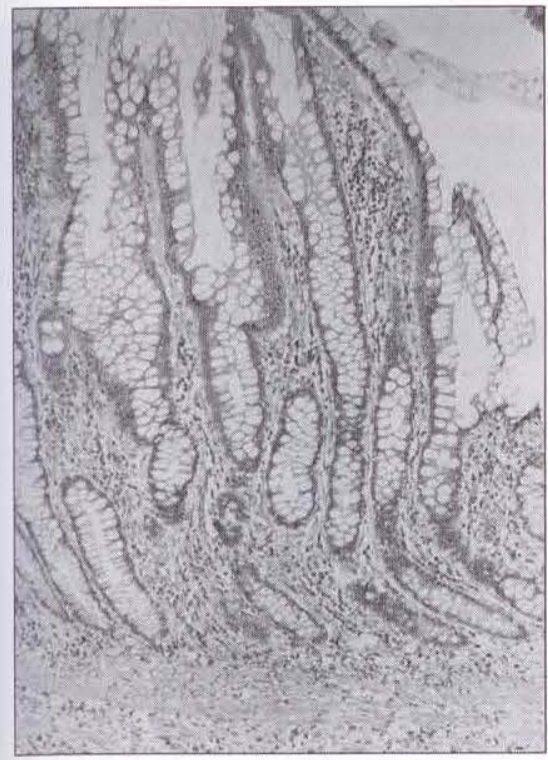

Figure 3) Photomicrograph of ileal section showing submucosal infiltration with signet ring cells. (Hematoxylin and eosin $\times 100$ )

cates that survival in patients with signet ring cell cancer of the colon is similar to that of patients with the more typical histological variety of colonic adenocarcinoma (6), suggesting the growth rate of signet ring cell colonic carcinoma may not be exceptionally rapid.

The patient's barium enema showed impressive contraction of the cecum, narrowing of the ascending colon and a stenotic ileocecal valve. There were calcified abdominal lymph nodes and chest radiographs were consistent with prior granulomatous disease.

These radiographs were nonspecific, but taken with the country of origin of the patient and her history of exposure to tuberculosis, intestinal tuberculosis involving the ileocecal region was considered. It was estimated that 80 to $90 \%$ of patients with intestinal tuberculosis will have involvement of the ileocecal region, possibly because of the rich lymphatic supply in this region.

However, in a review of 81 cases of abdominal tuberculosis in Canada, including patients with tuberculous peritonitis (7) only $21 \%$ had ileocecal involvement. Of these cases, 59\% had evidence of tuberculosis elsewhere. Thus, the absence of pulmonary changes indicative of active tuberculosis will not necessarily alter the initial radio-

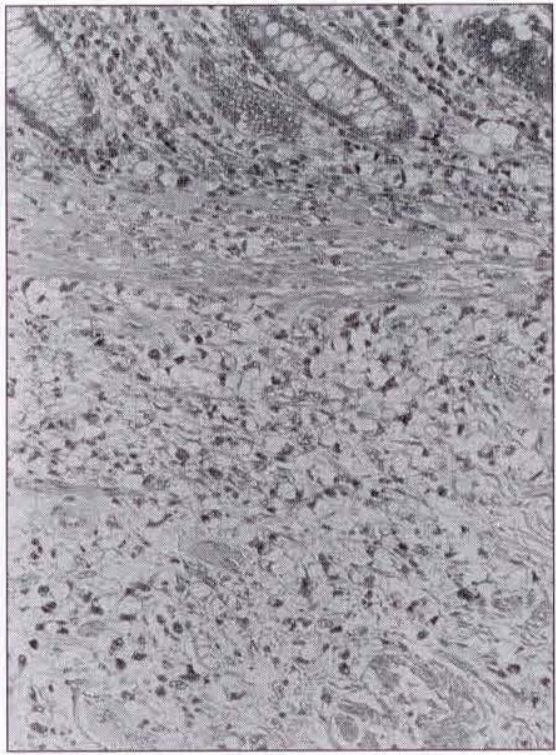

Figure 4) Higher power photomicrograph of submucosa of ileal section showing signet ring cell infiltrating muscularis mucosa. (Hematoxylin and eosin $\times 200$ )

logic interpretation. The classic radiological appearance of ileocecal tuberculosis is a conical, shrunken, contracted cecum with a narrow, ulcerated terminal ileum. Because of mesocolon contraction, the cecum may be pulled out of iliac fossa. With more advanced disease and stricturing of the ileocecal valve, dilation of the terminal ileum occurs $(8,9)$, and deep ulcerations, fissures and fistulous tracts may develop.

The radiological mimicry of ileocecal tuberculosis in this case is produced by the propensity of the signet ring carcinoma cells to infiltrate the bowel wall resulting in marked narrowing of the colon over a considerable distance with rigidity and fixation $(10,11)$. In the present patient the tumour infiltrated the cecal wall, ileocecal valve and terminal ileum, with barium enema changes resulting. Alternative radiological diagnoses included other inflammatory conditions, such as Crohn's disease or ischemic disease. For signet ring cell carcinoma occurring elsewhere in the colon, barium enema changes may simulate spasm, Crohn's disease, ischemic colitis with stricture and complicated diverticular disease $(5,12,13)$.

Tuberculous involvement of the colon aside from the ileocecal region can produce varied radiographic and

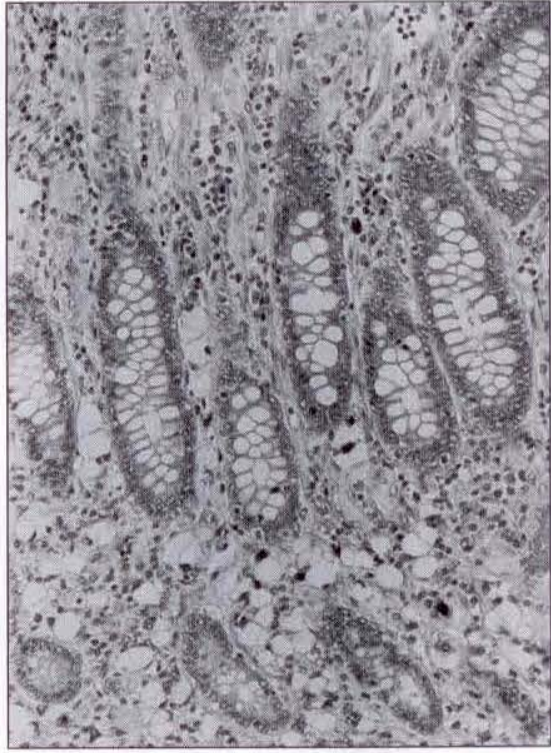

Figure 5) Photomicrograph of ileal section showing signet ring cell carcinoma infiltrating lamina propria pericryptal region. (Hematoxylin and eosin $\times 200$ )

endoscopic appearances, including segmental strictures, ulcerations or hypertrophic nodular mucosa (14). The endoscopic appearance of the right colon in the patient comprised abnormal, hemorrhagic mucosa but because of the degree of bleeding and friability encountered, adequate visualization was not possible. However, no large ulceration was encountered.

Signet ring cell carcinoma of the small intestine also is quite rare; however, it has been described in Crohn's disease (15), ileostomy stoma $(16,17)$ and in an ileal segment following ileocystoplasty (18). Spreading of the signet ring cells into the terminal ileum in the patient was expected, given the biological nature of this tumour as reflected by the in vitro observations demonstrated for the signet ring cell carcinoma cell line, DLD-2; this line showed increased invasiveness through basement membrane compared with other colonic epithelial cell lines (19).

This case illustrates that in signet ring cell carcinoma of the colon, the biological behaviour of the malignant cells can result in an unusual constellation of barium radiographic findings that may simulate other inflammatory diseases, particularly infection including ileocecal tuberculosis. 


\section{REFERENCES}

1. Mortel CG, Fleming TE, MacDonald JS, et al. Levasimole and fluorouracil for adjuvant therapy of resected colon carcinoma. N Engl J Med 1990;322:352-8.

2. Laufman H, Saphir O. Primary linitis plastica type of carcinoma of the colon. Arch Surg 1951;62:79-91.

3. Lui IOL, Kung ITM, Lee JMH, Boey $\mathrm{JH}$. Primary colorectal signet-ring carcinoma in young patients. Report of 3 cases. Pathology 1985;17:31-5.

4. Fahl JC, Dockerly MD, Judd ES. Scirrhous carcinoma of the colon and rectum. Surg Gynecol Obstet 1960;111:759-66.

5. Kwan WCP, Freeman HJ. Signet-ring cell carcinoma of the colon radiologically simulating Crohn's colitis. Can J Gastroenterol 1991;5:71-4

6. Giacchero A, Aste H, Baracchini P, et al. Primary signet-ring carcinoma of the large bowel. Report of nine cases. Cancer 1985;56:2723-6.
7. Jakubowski A, Elwood RK, Enarson DA. Clinical features of abdominal tuberculosis. J Infect Dis 1988; 158:687-92.

8. Anscombe AR, Keddie NC, Schofield PF. Caecal tuberculosis. Gut $1967 ; 8: 337-43$

9. Reeder MM, Palmer PES. Alimentary Tract Radiology, vol 2, 4th edn. In: Margulis AR, Burhene HJ, eds. St Louis: CV Mosby Co, 1989:1478-81.

10. Raskin MM. Some specific radiological findings and considerations of linitis plastica of the gastrointestinal tract. CRC Crit Rev Clin Radiol Nucl Med 1976;8:87-106

11. Wolff BS, Marchak RE. Linitis plastica or diffusely infiltrating type of carcinoma of the colon. Radiology 1983;81:502-7.

12. Jacobi MA. Primary linitis plastica carcinoma of the colon. Wisconsin Med J 1970;69:211-3.

13. Nelson PG. Primary linitis plastica carcinoma of the colon. Aust NZ J Surg 1965;34:288-91.

14. Aoki G, Nagasako K, Nakae Y, Suzuki
H, Endo M, Takemoto T. The fibercolonoscopic diagnosis of intestinal tuberculosis. Endoscopy 1975;7:112-21.

15. Petras RE, Mir-Madjlessi SH, Farmer RG. Crohn's disease and intestinal carcinoma. Gastroenterology 1987;93:1307-14.

16. Johnson CD. Primary mucinous adenocarcinoma developing in an ileostomy stoma. Gut 1989;30:889

17. Smart PJ, Sastry S, Wells S. Primary mucinous adenocarcinoma developing in an ileostomy stoma. Gut 1988;29:1607-12.

18. Takasaki E, Murahashi I, Toyoda M, Honda M, Waku S. Signet ring adenocarcinoma of ileal segment following ileocystoplasty. J Urol 1981;130:562-3.

19. Daneker GW Jr, Piazza AJ, Steele GD Jr, Mercurio AM. Interactions of human colorectal carcinoma cells with basement membranes. Analysis and correlation with differentiation. Arch Surg 1979;124:183-7. 


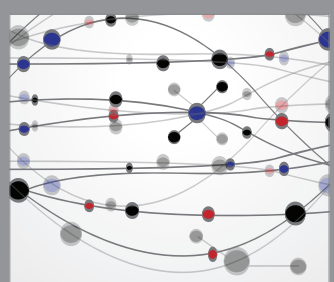

The Scientific World Journal
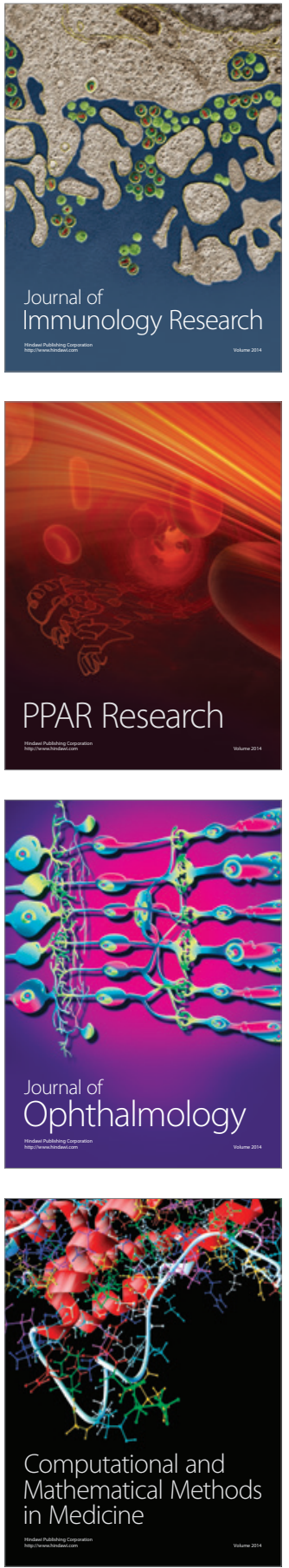

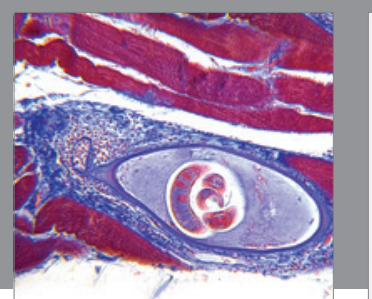

Gastroenterology Research and Practice

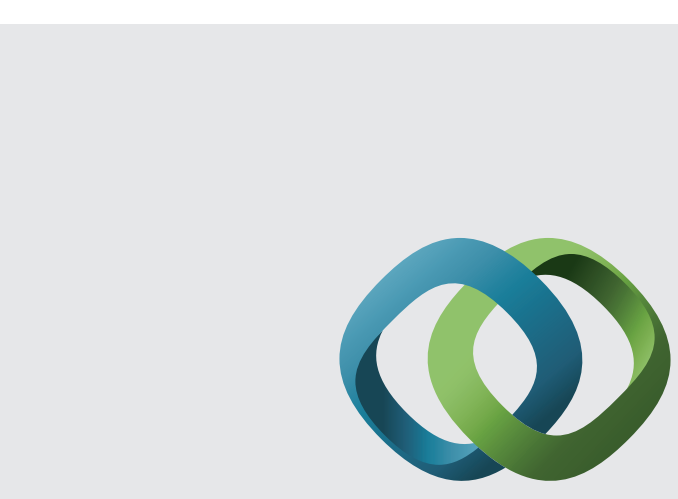

\section{Hindawi}

Submit your manuscripts at

http://www.hindawi.com
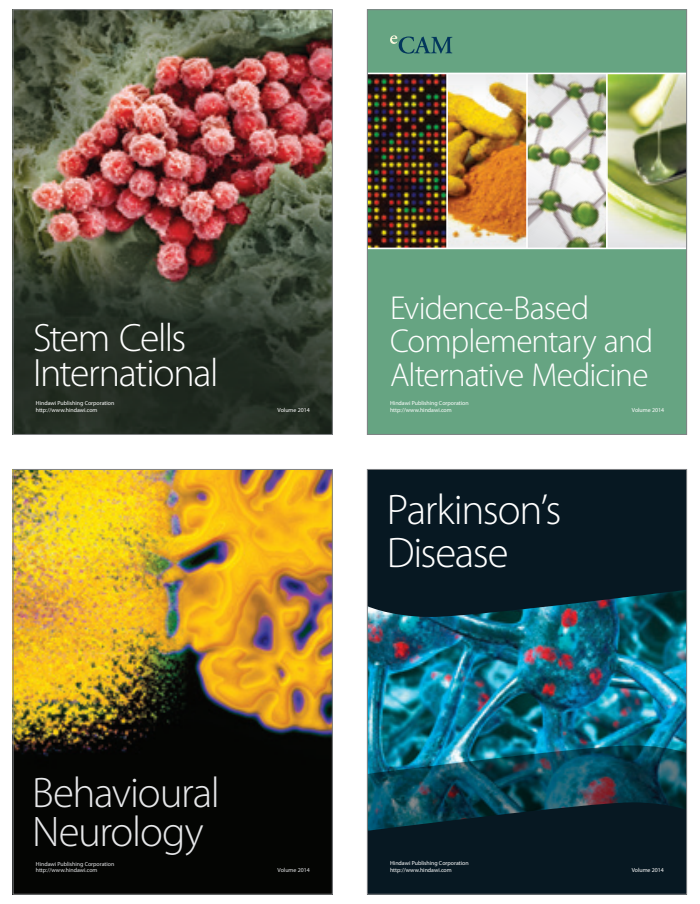
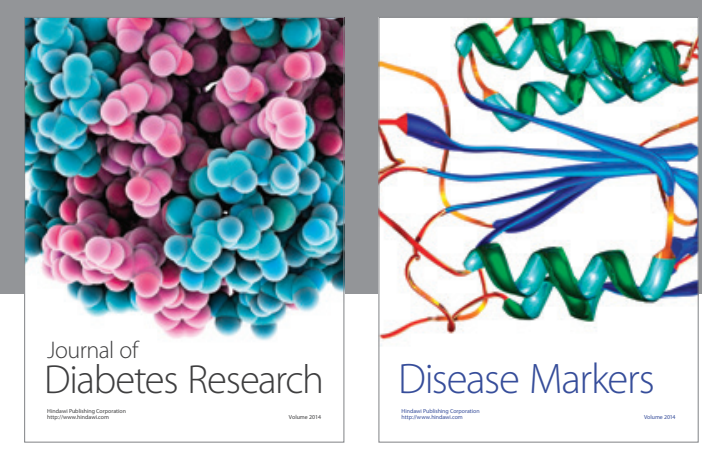

Disease Markers
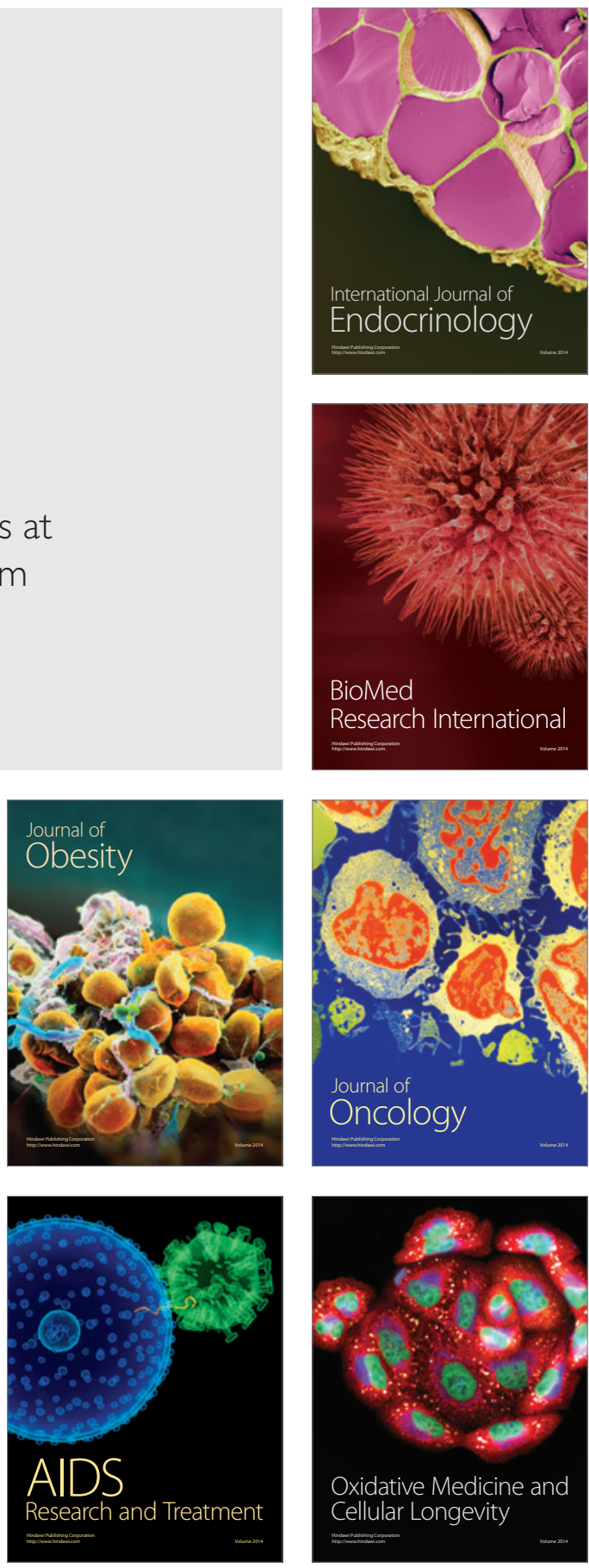